\title{
Avaliação da laminina-332 na tumorigênese de carcinoma de células escamosas orais: uma revisão de literatura
}

\author{
Evaluation of laminin-332 in tumorigenesis of oral squamous cell carcinoma: a literature review
}

\begin{abstract}
Eline Manhães Reid Silva, ${ }^{1}$ Letícia Côgo Marques, ${ }^{1}$ Kristian Cláudio Callegari, ${ }^{2}$ Letícia Nogueira da Gama de Souza ${ }^{1}$
${ }^{1}$ Departamento de Morfologia, Faculdade de Odontologia, Universidade Federal do Espírito Santo, Vitória, ES, Brasil

${ }^{2}$ Departamento de Odontologia, Faculdade de Odontologia, Universidade Federal Fluminense, Niterói, RJ, Brasil

- Os autores declaram que não há conflito de interesse.
\end{abstract}

\section{Resumo}

Objetivo: verificar se a laminina-332 é um marcador de alterações em processos iniciais da carcinogênese. Material e Métodos: trata-se de uma revisão da literatura, realizada a partir da seleção e análise de artigos originais e de revisão, publicados entre os anos de 1997 a 2013 no portal eletrônico Pubmed, Academic Google e portal de periódicos da Coordenação de Aperfeiçoamento de Pessoal de Nível Superior (CAPES). Resultados: foram selecionados 36 artigos através dos descritores: "oral"; "squamous cell carcinoma"; "laminin-332 ou laminin-5", "oral dysplastic cells" "potentially malignant disorders" que correlacionaram o avanço, progressão e/ ou invasão, do processo de progressão tumoral com a laminina-332 ou a expressão dessa glicoproteína em displasias e carcinoma oral. Conclusão: a variação da apresentação da laminina-332 apresentou relação direta com a evolução do câncer. Assim, compreender o papel dessa molécula na biologia tumoral pode auxiliar no entendimento da progressão da doença. Palavras-chave: Laminina-332 ou laminina-5; Carcinoma de células escamosas; Desordens potencialmente malignas.

\section{AbstRAct}

Objective: to verify if laminin-332 is a marker of alterations in early processes of carcinogenesis. Material and Methods: this is a review of the literature, based on the selection and analysis of original articles and review, published between 1997 and 2015 in the electronic portal PubMed, Academic Google and periodical portal of the Coordination of Improvement of Personnel of Higher Education (CAPES). Results: 36 articles were selected using the descriptors: "oral"; "Squamous cell carcinoma"; "Laminin-332 or laminin-5," "oral dysplastic cells," "potentially malignant disorders" that correlated the progression, progression and / or invasion of the tumor progression process with laminin-332 or the expression of that glycoprotein in dysplasias and carcinoma oral. Conclusion: the variation of the presentation of laminin-332 was directly related to the evolution of cancer. Thus, understanding the role of this molecule in tumor biology may help in understanding the progression of the disease.

Keywords: Laminin-332 or laminin 5; Squamous cell carcinoma; Potentially malignant disorders.

\section{Introdução}

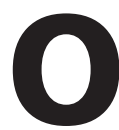
câncer de boca ficou entre os 5 mais incidentes em homens e 12 entre as mulheres para o ano de $2014 . .^{1} \mathrm{O}$ carcinoma oral de células escamosas (CCE) também conhecido como carcinoma espinocelular, é a neoplasia maligna de origem epitelial com maior índice de ocorrência na cavidade oral, ocupando, aproximadamente, $90-95 \%$ de todas as neoplasias nessa região. ${ }^{2}$ Pode desenvolver-se a partir de carcinoma in situ (CIS) ou desordens orais com potencial de malignização (DOPMs), como leucoplasia e eritroplasia, apresentando graus de diferenciação histológica. ${ }^{3}$

O CCE pode ser encontrado em qualquer sítio da boca e muitos fatores de risco estão associados ao aumento de sua incidência. O hábito de fumar e o consumo de álcool são fatores bem reconhecidos pela literatura. Isolados, esses fatores podem aumentar de duas a três vezes o risco de CCE. ${ }^{4}$

A displasia epitelial oral (DEO) é caracterizada por variação morfológica e celular nos tecidos que são similares àquelas que acontecem no CCE. São restritas ao epitélio e permanecem como uma condição não invasiva. Ela descreve um estágio pré-canceroso e sua avaliação histopatológica é um fator preditivo para a transformação maligna de DOPMs. ${ }^{5}$ Quando DOPMs apresentam a DEO e não são interceptadas precocemente, podem evoluir para CIS e até mesmo o CCE. ${ }^{6}$

$\mathrm{Na}$ interface entre o epitélio e o tecido conjuntivo está a membrana basal (MB). Inicialmente, essa estrutura foi considerada como uma barreira protetora contra a invasão do câncer, com a função de impedir a invasão das células tumorais aos tecidos sub- jacentes. ${ }^{7}$ No entanto, trabalhos demonstraram que a MB é uma estrutura bastante dinâmica no processo tumoral. ${ }^{8}$ Ela funciona como um complexo de proteínas ligantes e fatores de crescimento que influencia no comportamento do microambiente. São componentes que fazem parte da MB: colágeno tipo IV, laminina, perlecan, nidogen (entactina) e outras moléculas específicas. ${ }^{9}$

A laminina-332 é uma grande glicoproteína extracelular e importante componente da $\mathrm{MB} \cdot{ }^{10} \mathrm{~A}$ molécula de laminina é um heterotrímero em formato de cruz, consistindo de três cadeias polipeptídicas ligadas por pontes dissulfeto: uma cadeia pesada ( $\alpha$ ) e duas cadeias leves $(\beta$ e $\gamma)$. O papel da laminina-332 em adesão de células epiteliais é tão fundamental que alteração no gene Lam 3 no período de embriogênese leva ao aparecimento de doenças incompatíveis com a vida. ${ }^{11}$

Dentro do contexto da tumorigênese, a laminina-332 vem recebendo destaque. Trabalhos realizados em diferentes tipos de tumores epiteliais mostraram uma mudança na sua distribuição, com uma perda local na $\mathrm{MB}$ e deposição no estroma próximo às células neoplásicas invasoras, em particular quando a lesão apresenta comportamento agressivo. ${ }^{12}$

Assim, o objetivo deste trabalho foi verificar se a laminina-332 é um marcador de alterações em processos iniciais da carcinogênese.

\section{Material e Métodos}

Os artigos que foram empregados para efetuar esta revisão de literatura foram selecionados no portal eletrônico PubMed, Academic Google e portal de periódicos da Coordenação de Aperfei- 
çoamento de Pessoal de Nível Superior (CAPES) abrangendo trabalhos entre 1997 e 2013. As seguintes etapas foram observadas: identificação da proposta, busca na literatura no período de outubro de 2015, avaliação dos estudos, exclusão de estudos não pertencentes ao tema, análise crítica dos resultados e interpretação. A figura 1 mostra o fluxograma de confecção do artigo.

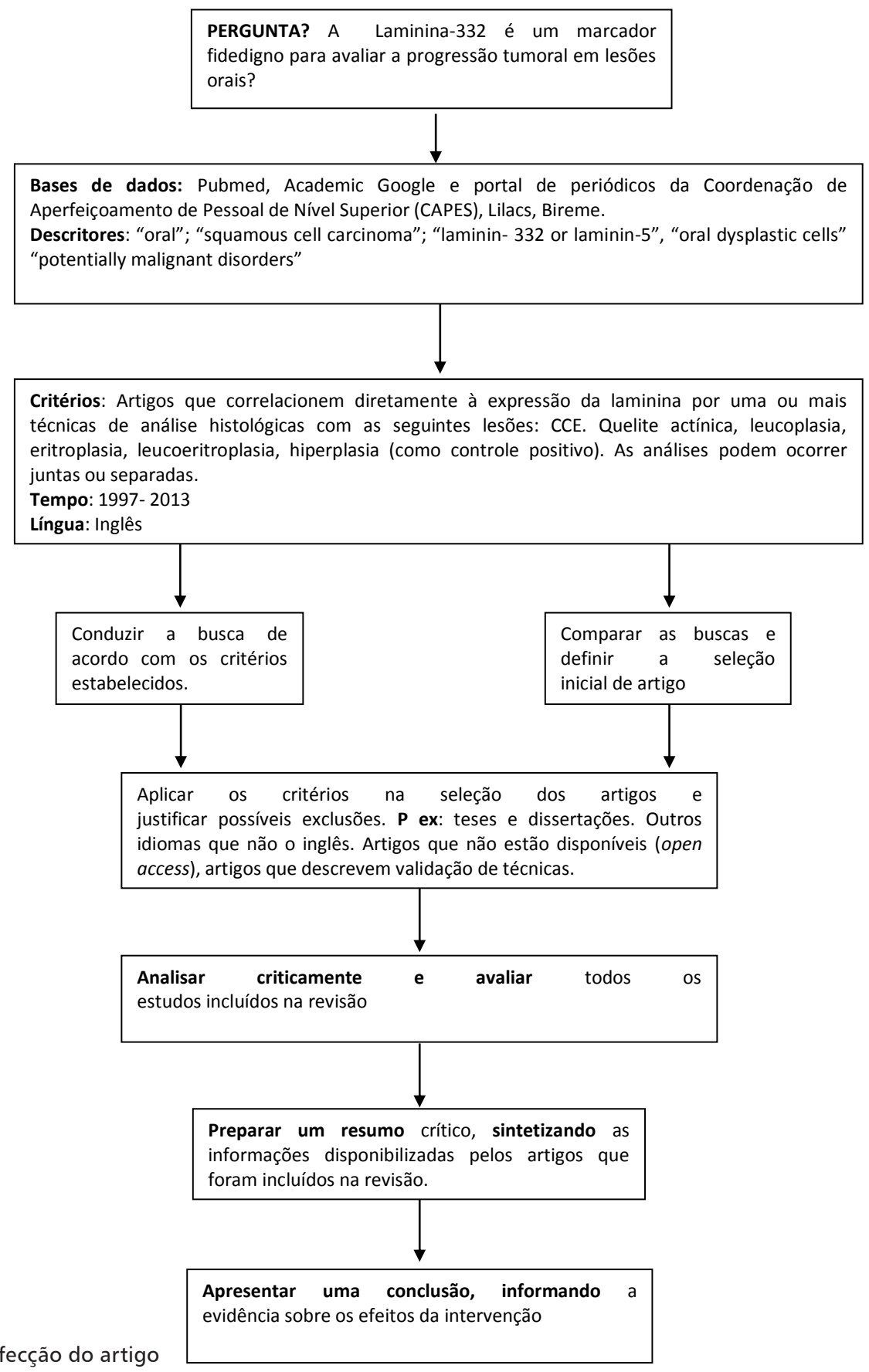

Figura 1. Fluxograma da confecção do artigo

Os critérios de inclusão foram: publicação na língua inglesa, textos completos que tivessem em seu título ou resumo os seguintes descritores: "oral”; "squamous cell carcinoma”; "laminin-332 or laminin-5”, “oral dysplastic cells" "potentially malignant disorders" e que correlacionassem o avanço (progressão/invasão) do processo de tumoral com a laminina-332 ou a expressão dessa glicoproteína em displasias e carcinoma oral. Foram excluídos da pesquisa teses e dissertações, bem como artigos que ao serem analisados não se enquadravam na temática proposta. Para a introdução do artigo e seu enriquecimento, também foram incluídos: artigos de revisão de literatura que mencionavam laminina-332 e estudos com sua expressão em carcinomas de outras regiões do corpo humano. Foram selecionados 36 artigos e após a leitura completa destes, 26 foram excluídos por não atenderem aos requisitos anteriores.

\section{Resultados}

Os principais resultados referentes à imunomarcação da laminina-332 estão resumidos na tabela 1. 
Tabela 1. Resultados dos estudos referentes à imunomarcação da laminina-332

\begin{tabular}{|c|c|c|c|c|c|}
\hline \multirow{2}{*}{$\begin{array}{l}\text { Mucosa normal } \\
\text { Hiperplasia Fibrosa } \\
\text { Inflamatória }\end{array}$} & \multirow{2}{*}{$\begin{array}{l}\text { Mucosa normal Hiperpla- } \\
\text { sia Fibrosa Inflamatória }\end{array}$} & \multicolumn{3}{|c|}{ Displasias } & \multirow{2}{*}{ CCE } \\
\hline & & Baixo Grau & Moderado & Alto Grau & \\
\hline $\begin{array}{l}\text { Marcação negativa } \\
\text { I. (Gasparoni): } 10 \\
\text { casos; } \\
\text { II. (Lindberg: } 17 \\
\text { casos); } \\
\text { III. (Shruthy: } 1 \text { caso) } \\
\text { IV. (Thorup: } 6 \text { casos) } \\
\text { Total artigos }=4 \\
\text { Total de casos }=34\end{array}$ & $\begin{array}{l}\text { Marcação negativa } \\
\text { I. (Rani: } 24 \text { casos); } \\
\text { II. (Thorup: } 5 \text { casos); } \\
\text { III. (Zargaran: } 15 \text { casos) } \\
\text { Total artigos }=3 \\
\text { Total de casos }=44\end{array}$ & $\begin{array}{l}\text { Marcação negativa } \\
\text { I. (Peixoto da Silva: } 16 \\
\text { casos); } \\
\text { II. (Rani: } 27 \text { casos); } \\
\text { III.(Gasparoni: } 65 \\
\text { casos) } \\
\text { Total artigos }=3 \\
\text { Total de casos }=108 \\
\text { casos }\end{array}$ & $\begin{array}{l}\text { Marcação negativa } \\
\text { I. (Rani: } 8 \text { casos) } \\
\text { Total artigos }=1 \\
\text { Total de casos }=8\end{array}$ & $\begin{array}{l}\text { Marcação negativa } \\
\text { I. (Rani: } 29 \text { casos) } \\
\text { II. (Peixoto da Silva: } \\
8 \text { casos) } \\
\text { Total artigos }=2 \\
\text { Total de casos }=37\end{array}$ & $\begin{array}{l}\text { Marcação MB/ estroma } \\
\text { I. (Kosmehl: } 27 \text { casos de MB com irregularidades e } \\
\text { marcação intracitoplasmática); } \\
\text { II. (Lindberg: } 20 \text { casos de marcação intracitoplas- } \\
\text { mática em células tumorais e nenhuma marcação } \\
\text { estromal ou extracelular); } \\
\text { III. (Shruthy: } 19 \text { casos apresentaram MB com } \\
\text { marcação contínua e } 21 \text { com coloração intracitoplas- } \\
\text { mática); } \\
\text { IV. (Thorup: } 18 \text { casos com marcação da laminina-5 } \\
\text { com pequenos grânulos e minúsculas fibras curtas no } \\
\text { tecido conjuntivo ou com a duplicação da MB); } \\
\text { V. (Lindberg: Células marcadas para laminina-332 } \\
\text { eram solitárias ou em forma de cordão em carcinoma } \\
\text { grau } 1 \text { ( } n=11 \text { ) / em grau } 2 \mathrm{n}=19 \text { ); } \\
\text { VI. (Haas: } 18 \text { casos com MB fraca ou descontínua). } \\
\text { Total artigos = } 6 \\
\text { Total de casos }=\text { MB contínua ou duplicada } 45 \text { / } \\
\text { Intracitoplasmático } 117\end{array}$ \\
\hline $\begin{array}{l}\text { Marcação restrita à MB } \\
\text { I. (Haas: } 4 \text { casos); } \\
\text { II. (Kainulainen: } 4 \\
\text { casos); } \\
\text { III. (Shruthy: } 1 \text { caso); } \\
\text { IV. (Kosmehl: } 10 \\
\text { casos). } \\
\text { Total artigos }=4 \\
\text { Total de casos }=19 \\
\text { casos }\end{array}$ & $\begin{array}{l}\text { Marcação restrita à MB } \\
\text { I. (Haas: } 6 \text { casos de } \\
\text { MB com irregularidades e } \\
\text { aumento de espessura). } \\
\\
\text { Total artigos }=1 \\
\text { Total casos }=6\end{array}$ & $\begin{array}{l}\text { Marcação restrita à MB } \\
\text { I. (Lindberg: } 6 \text { casos } \\
\text { com marcação da MB } \\
\text { contínua e irregularida- } \\
\text { des leves). } \\
\\
\quad \text { Total artigos }=1 \\
\text { Total de casos }=6\end{array}$ & & $\begin{array}{l}\text { Marcação restrita à MB } \\
\text { I. (Kainulainen: } 9 \text { casos } \\
\text { com descontinuidade } \\
\text { na MB); } \\
\text { II. (Kosmehl: } 3 \text { casos a } \\
\text { MB tornaram-se turva e } \\
\text { com irregularidades); } \\
\text { III. (Thorup: } 18 \text { casos } \\
\text { com duplicação da MB e } \\
\text { marcação no conjuntivo). } \\
\text { Total artigos }=3 \\
\text { Total de casos }=30\end{array}$ & $\begin{array}{l}\text { Marcação ninhos e fronts: } \\
\text { I. (Gasparoni: } 65 \text { casos com ninhos, fronts e } \\
\text { abaixo de áreas inflamatórias); } \\
\text { II. (Kainulainen: } 12 \text { casos com marcação localizada } \\
\text { dentro de células malignas nos fronts e ninhos e } \\
\text { todas as células do estroma sendo negativa para } \\
\text { Lan-332); } \\
\text { III. (Kosmehl: } 27 \text { casos com marcação na periferia } \\
\text { de ninhos e fronts com MB descontínua e marcação } \\
\text { no estroma); } \\
\text { IV. (Lindberg: } 18 \text { casos com marcação nas células } \\
\text { basais de ninhos); } \\
\text { V. (Peixoto da Silva: } 5 \text { casos com marcação intraci- } \\
\text { toplasmática na periferia do front com expressão não } \\
\text { homogênea); } \\
\text { VI. (Thorup: } 18 \text { casos com padrão da laminina } \\
\text { irregular ou perda total de coloração da MB, a dupli- } \\
\text { cação da MB, ou o excesso de material no estroma); } \\
\text { VII. (Zargaran: Em ninhos - } 15 \text { marcaçães de } \\
\text { células na perifieria do tumor) } \\
\text { Total artigos = } 7 \\
\text { Total de casos = } 160\end{array}$ \\
\hline $\begin{array}{l}\quad \begin{array}{l}\text { Intensidade da } \\
\text { marcação }\end{array} \\
\text { 99-100\% } \\
\text { I. (Haas: } 4 \text { casos) } \\
\text { Total de artigos }=1 \\
\text { Total de casos }=4\end{array}$ & $\begin{array}{l}\text { Intensidade da } \\
\text { marcação } \\
107 \% \text { a } 114 \% \\
\text { I. (Haas: } 6 \text { casos de HFI); } \\
\text { II. (Rani: }-0,15 \text { pixels } 24 \\
\text { casos de HFI). } \\
\text { Total de artigos }=2 \\
\text { Total de casos }=30\end{array}$ & $\begin{array}{l}\text { Intensidade da } \\
\text { marcação } \\
0,00 \\
\text { I. (Rani: } 0,00 \text { pixel } 27 \\
\text { casos). } \\
\text { Total artigos }=1 \\
\text { Total de casos }=27\end{array}$ & $\begin{array}{l}\text { Intensidade da } \\
\text { marcação } \\
0,06 \\
\text { I. (Rani: }-0,06 \text { pixels } \\
8 \text { casos). } \\
\text { Total artigos }=1 \\
\text { Total de casos }=8\end{array}$ & $\begin{array}{l}\text { Intensidade da marcação } \\
0,003 \\
\text { I. (Rani: }-0,003 \text { pixels } \\
29 \text { casos). } \\
\text { Total artigos }=1 \\
\text { Total de casos }=29\end{array}$ & $\begin{array}{l}\text { Intensidade da marcação } \\
\text { 48-9, } \\
\text { I. (I-Rani } 48 \text { casos com 9,14 pixels); } \\
\text { II. (Zargaran: } 13 \text { casos com marcação fraca - car- } \\
\text { cinoma verrucoso e } 13 \text { casos com marcação intensa } \\
\text { - CCE); } \\
\text { III. (Haas: } 5 \text { casos de CCE bem diferenciado com } \\
65 \% \text { de intensidade, } 6 \text { casos de MB com } 55 \% \text { de } \\
\text { intensidade e } 7 \text { casos PD com } 40 \% \text { de intensidade). } \\
\text { Total artigos }=3 \\
\text { Total de casos }=\text { Intensidade baixa = } 18 \text { e Intensi- } \\
\text { dade alta }=74\end{array}$ \\
\hline $\begin{array}{l}\text { Hibridização in situ } \\
\text { I. (Kainulainen: sem } \\
\text { sinal) } \\
\text { Total de casos }=4 \\
\text { Total de artigos }=1\end{array}$ & & $\begin{array}{l}\text { Hibridização in situ } \\
\text { I. (Kainulainen: } 6 \\
\text { casos com hibridização in } \\
\text { situ presente em células } \\
\text { epiteliais basais). } \\
\text { Total artigos }=1\end{array}$ & & $\begin{array}{c}\text { Hibridização in situ } \\
\text { I. (Kainulainen: } 9 \text { casos } \\
\text { com hibridização in situ } \\
\text { presente em células epite- } \\
\text { liais basais). } \\
\text { Total artigos }=1 \\
\text { Total de casos }=6\end{array}$ & $\begin{array}{l}\text { Hibridização in situ } \\
\text { I. (Kainulainen: } 12 \text { casos sinal exclusivo em células } \\
\text { malignas do front e ilhas e sem sinal no estroma). } \\
\text { Total artigo }=1 \\
\text { Total casos }=12\end{array}$ \\
\hline \multirow[t]{2}{*}{$\begin{array}{l}\text { Quantificação da } \\
\text { marcação } \\
\text { I. (Gasparoni): } \\
62 \text { casos - menos do } \\
\text { que } 10 \text { células marcadas } \\
3 \text { casos entre } 11 \text { e } 30 \\
\text { células marcadas e } 1 \text { caso } \\
\text { com mais do que } 50 \\
\text { Total de artigos }=1\end{array}$} & & \multicolumn{2}{|c|}{$\begin{array}{l}\text { Quantificação da marcação } \\
\text { I. (Gasparoni): } 55 \text { casos com menos do que } 10 \\
\text { células marcadas; } 11 \text { casos com } 11 \text { a } 30 \text { células } \\
\text { marcadas e nenhum caso com mais do que } 50 \\
\text { células marcadas } \\
\text { Total de artigos }=1\end{array}$} & & $\begin{array}{l}\text { Quantificação marcação } \\
\text { I. (Gasparoni) } 37 \text { amostras }<10 \text { células marcadas, } \\
22 \text { amostras entre } 21 \text { a } 50 \text { e } 6 \text { amostras menor que } \\
50 \text { células. } \\
\text { II. (Zargaran) } 12 \text { amostras com menos do que } \\
5 \% \text { de células marcadas (Carcinoma Verrucoso) } \\
\text { e } 13 \text { amostras tiveram mais do que } 5 \% \text { de células } \\
\text { marcadas - CCE } \\
\text { Total de artigos = } 2\end{array}$ \\
\hline & & & & & $\begin{array}{l}\text { Sobrevida do paciente } \\
\text { Gasparoni } \\
\text { Os que tinham menos do que } 10 \text { células marcadas: } \\
67.45 \text { meses; } \\
\text { Entre } 11 \text { e } 40 \text { células marcadas: sobrevivência } \\
\text { de } 39,4 \text { meses; com mais de } 50 \text { células marcadas: } \\
\text { sobrevida de } 17,8 \text { meses. }\end{array}$ \\
\hline
\end{tabular}




\section{A Imunomarcação da Cadeia $\gamma 2$ da Laminina-332 na Mucosa Normal, Hiperplasia Fibrosa Inflamatória, Displasias e CCEs}

$\mathrm{Na}$ mucosa normal sem alterações, $64 \%$ dos casos não apresentaram marcação referente à laminina-332 e 36\% apresentaram marcação restrita à MB. Com relação à hiperplasia fibrosa inflamatória, que em muitos artigos era usada como controle negativo, mostrou-se com marcação negativa em $88 \%$ dos casos e em $12 \%$ com marcação restrita à MB. Estes casos com marcação positiva de hiperplasia fibrosa inflamatória estão relacionados a um artigo que relatou espessamento da membrana com irregularidades com análise por imunofluorescência confocal. As displasias foram separadas em baixo, moderado e de alto grau. Nas primeiras foram verificados aspectos negativos em $97 \%$ e apenas $3 \%$ apresentaram marcação restrita à $\mathrm{MB}$, sendo esta contínua e regular. Na displasia moderada, $100 \%$ dos casos (relatados por um único artigo) foram negativos. As displasias de alto grau apresentaram $55 \%$ dos casos com marcação negativa e $45 \%$ com marcação positiva, variando em aspecto descontínuo, irregular ou duplicação da MB concomitantemente à marcação no tecido conjuntivo. Nos CCEs houve alguns aspectos relevantes: $49 \%$ apresentaram fronts invasivos com marcação do tecido conjuntivo adjacente e descontinuidade ou ausência da $\mathrm{MB}$ e/ou ninhos tumorais, este último apresentou marcação mais acentuada na periferia e nenhuma marcação no centro. Em 36\% dos casos a marcação foi citoplasmática nas células tumorais e 15\% apresentaram MB contínua ou duplica$\mathrm{da}$, este último aspecto mostrou-se mais evidenciado em CCEs bem diferenciados.

\section{Aspecto Relacionado à Quantificação, Intensidade e Hibridização in situ de Células Marcadas}

Em relação à quantificação de células marcadas, a mucosa normal apresentou em $93 \%$ dos casos menos que 10 células marcadas. Apenas $2 \%$ dos casos apresentaram uma quantificação acima de 50 células marcadas.

Com relação aos casos de displasias, $83 \%$ apresentaram-se com marcação em menos de 10 células. Os outros $17 \%$ apresentaram expressão em uma quantidade de 11 a 30 células.

Nos CCEs, Gasparoni et al. ${ }^{13}$ descreveram expressão em menos de 10 células em 56\% dos casos. Em 33\% dos casos, a marcação ficou entre 21 a 50 células. Os demais $11 \%$ dos casos demonstraram uma expressão em mais de 50 células. Já Zargaran et al., ${ }^{24}$ descreveram que em $56 \%$ dos casos houve expressão em menos de 5 células. Gasparoni et al. ${ }^{13}$ destacaram a relação positiva entre células marcadas e sobrevida. Quando o paciente tinha menos que 10 células marcadas a média de sobrevida foi de 67,4 meses, em contrapartida quando havia mais do que 50 células marcadas a média de sobrevivência caiu para 17,8 meses. Em relação à hibridização in situ, $100 \%$ dos casos não mostraram nenhum sinal na mucosa normal, nas displasias $100 \%$ mostraram sinalização nas células epiteliais da camada basal e nos CCEs $100 \%$ dos casos mostraram sinalização nos fronts e ilhas e ausência de sinalização no estroma. Consoante à intensidade com imunofluorescência confocal, a predileção foi decrescente com a MB mostrando maior intensidade (99-10\%) e os carcinomas mostrando perda de intensidade na MB (4060\%). Quando o aspecto foi a análise da marcação nas células, a mucosa normal e displasias mostraram marcação ausente e fraca, respectivamente, e em análise entre carcinoma verrucoso e CCE, este mostrou marcação intensa em $100 \%$ dos casos e aquele marcação fraca em $100 \%$ dos casos.

\section{Discussão}

Um importante passo na progressão do câncer são as alterações que afetam a MB e sua densa rede de glicoproteínas. ${ }^{9} \mathrm{~A}$ laminina-332 desempenha múltiplas funções biológicas e tem sido associada com a progressão do tumor em uma variedade de neoplasias epiteliais malignas. ${ }^{25,26}$

Estudos recentes mostraram que a atividade biológica da laminina-332 é modulada pelo processamento da cadeia $\gamma 2 \mathrm{e}$ $\alpha 3,{ }^{18,27}$ por ação de enzimas proteolíticas denominadas metaloproteinases de matriz (MMPs). Ou seja, sua clivagem gera uma isoforma com atividade celular aumentada. A presença da molécula foi observada em células cancerígenas localizadas na interface tumor/estroma em alguns tipos de carcinomas, sugerindo que ela possa exercer importante função na motilidade celular. Portanto, a laminina-332 pode atuar sob certas circunstâncias como um elemento chave para adesão celular, mas em outras vezes como promotor de motilidade. ${ }^{28}$ Outro aspecto relacionado a essa glicoproteína é sua capacidade em promover potente migração celular. No reparo de feridas, por exemplo, ela é sobre-expressa pelos queratinócitos. ${ }^{29,30}$

Embora o aumento de sua expressão na invasão tumoral tenha sido observado, não se sabe que mecanismo está por trás da regulação desses dois eventos biológicos paradoxais, adesão $\mathrm{X}$ migração, quando se está diante de células consideradas estáveis. ${ }^{31}$ Assim, para a elucidação desse processo, são necessários novos estudos que busquem avaliar aspectos funcionais e reguladores da laminina-332 no contexto da tumorigênese.

O padrão de marcação da laminina-332 frequentemente encontrado em tecidos normais ou hiperplasia, quando usado como controle, foi restrito à MB ou negativo, ${ }^{13,14,17,22,24}$ evidenciando que em situações de normalidade ou benignidade a MB está inalterada.

A invasão de carcinoma engloba o processamento da $\mathrm{MB}$, há muito tida como inerte, simultaneamente a formação de uma nova membrana, por vezes reduzida ou descontinuada. Isso se deve também a atividades proteolíticas da integrina $a 6 \beta 4$, principal receptor da laminina-332, essencial para formação de hemidesmossomos que mantêm a união entre os queratinócitos da camada basal e a MB.$^{15}$ Shruthy et al. ${ }^{22}$ mostraram que houve maior descontinuidade da $\mathrm{MB}$ em carcinomas pobremente diferenciados do que em bem diferenciados, sugerindo que há grande atividade proteolítica nas lesões mais agressivas, levan-

Rev. Bras. Odontol., Rio de Janeiro, v. 74, n. 1, p. 56-61, jan./mar. 2017 
do ao processamento da $\mathrm{MB}$ e consequentemente invasão e metástase.

Segundo Haas et al., ${ }^{14}$ uma redução da adesão da célula à $\mathrm{MB}$, por meio da laminina-332 em carcinomas, seria uma etapa comum no processo de invasão de células tumorais (figura 2). No entanto, em carcinomas pelo menos três padrões distintos de expressão desta glicoproteína foram encontrados, (1) expressão dentro de células tumorais de epitélio invasivo, (2) marcação em região em que havia processo de descontinuidade da MB e (3) marcação estromal, muitas vezes em locais abaixo de fronts invasivos. ${ }^{16,20,23}$ Essas características embora aparentemente distintas evidenciam um processo de transição epitéliomesenquimal em que a interação célula-célula e célula-ambiente é alterada permitindo assim a invasão tumoral (figura 2).

Kainulainen et al. ${ }^{15}$ avaliaram a expressão da laminina-332 através de hibridização in situ e evidenciaram aumento da expres- são em displasias e a forte expressão de RNA em CCEs orais, ao contrário do que se observou em mucosa normal e líquen plano, comprovando que há aumento dessa glicoproteína em situações patológicas.

Outra característica encontrada em muitos tumores foi a marcação da molécula em ninhos tumorais. Essa marcação foi mais evidente na periferia do tumor ao contrário do centro, sendo observado por muitos autores como um fenótipo celular de migração e invasão celular, com consequente pior prognóstico para o paciente. ${ }^{18,20}$

A intensidade da marcação também foi analisada em mucosa normal, displasia e carcinoma e foi demonstrado que quanto maior a alteração tecidual, mais acentuada foi a marcação. ${ }^{21,24}$ Trabalhos mostraram ainda que houve pior prognóstico de sobrevida para pacientes que tiveram mais células marcadas para laminina-332 em epitélio invasivo, ${ }^{13,19}$ embora não tenha havido relação com o estadiamento do tumor.

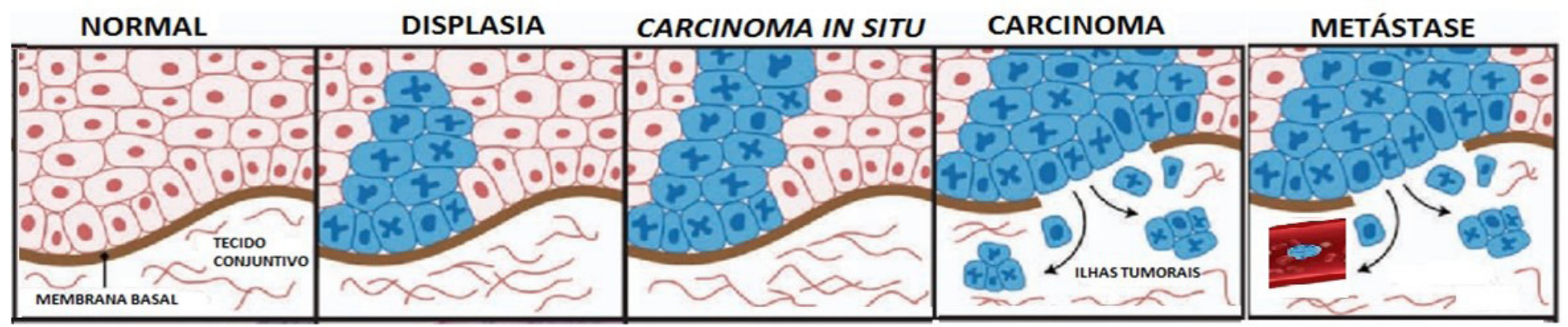

Figura 2. Ilustração esquemática do desenvolvimento celular da carcinogênese epitelial (SCANLON, et al. 2013/ Adaptado.32)

\section{Conclusão}

Embora nenhum marcador inicial ou uma molécula chave que represente a base de todo o processo tumoral tenha sido encontrada, pode-se dizer que a laminina-332 apresenta resultados relevantes, tanto em etapas precoces quanto em etapas avançadas do câncer e pode ser usada como possível biomarcador para o melhor entendimento da carcinogênese epitelial.

\section{Referências}

1. INCA: Instituto Nacional de Câncer José Alencar Gomes da Silva. Coordenação de Prevenção e Vigilância. Estimativa 2014: Incidência de Câncer no Brasil. Rio de Janeiro. 2014; 25:26-41.

2. Johnson NW, Jayasekara P, Amarasinghe AA. Squamous cell carcinoma and precursor lesions of the oral cavity: epidemiology and aetiology. Periodontol 2000. 2011;57(1):19-37.

3. Sato H, Higashi S, Miyazaki K. Amino-terminal fragments of laminin $\gamma 2$ chain stimulate migration of metastatic breast cancer cells by interacting with CD44. Clin Exp Metastasis. 2015;32(5):404-15.

4. Shenoi R, Devrukhkar V, Chaudhuri, Sharma BK, Sapre SB, Chukhale A. Demographic and clinical profile of oral squamous cell carcinoma patients: a retrospective study. Indian J Cancer. 2012;49(1):21-6.

5. Dost F, Lê Cao KA, Ford PJ, Farah CS. A retrospective analysis of clinical features of oral malignant and potentially malignant disorders with and without oral epithelial dysplasia. Oral Surg Oral Med Oral Pathol Oral Radiol. 2013;116(6):725-33. 6. Warnakulasuriya S, Reibel J, Bouquot J, Dabelsteen E. Oral epithelial dysplasia classification systems: predictive value, utility, weaknesses and scope for improvement. J Oral Pathol Med. 2008;37(3):127-33.

7. Liotta LA, Rao CN, Wewer UM. Biochemical interactions of tumor cells with the basement membrane. Annu Rev Biochem. 1986; 55:1037-57.

8. Lohi J. Laminin-5 in the progression of carcinomas. Int J Cancer. 2001;94(6):7637.

9.Kulasekara KK, Lukandu OM, Neppelberg E, Vintermyr OK, Johannessen AC, Costea DE. Cancer progression is associated with increased expression of basement membrane proteins in three-dimensional in vitro models of human oral cancer.
Arch Oral Biol. 2009;54(10):924-31.

10. Aumailley M, Bruckner-Tuderman L, Carter WG, Deutzmann R, Edgar D, Ekblom P, et al. A simplified laminin nomenclature. Matrix Biol. 2005;24(5):326-32. 11. Ryan MC, Christiano AM, Engvall E, Wewer UM, Miner JH, Sanes JR, et al. The functions of laminins: lessons from in vivo studies. Matrix Biol. 1996;15(6):369-81. 12. Berndt A, Hyckel P, Konneker A, Katenkamp D, Kosmehl H. Oral squamous cell carcinoma invasion is associated with a laminin-5 matrix re-organization but independent of basement membrane and hemidesmosome formation clues from an in vitro invasion model. Invasion Metastasis. 1997;17(5):251-8.

13. Gasparoni A, Della Casa M, Mililo L, Lorenzini G, Rubini C, Urso R, et al. Prognostic value of differential expression of Laminin-5 gamma 2 in oral squamous cell carcinomas: correlation with survival. Oncol Rep. 2007;18(4):793-800.

14. Haas KM, Berndt A, Stiller KJ, Hyckel P, Kosmehl H. A comparative quantitative analysis of laminin-5 in the basement membrane of normal, hyperplastic, and malignant oral mucosa by confocal immunofluorescence imaging. J Histochem Cytochem. 2001;49(10):1261-8.

15. Kainulainen T, Autio-Harmainen H, Oikarinen A, Salo S, Tryqqvason K, Salo T. Altered distribution and synthesis of laminin-5 (kalinin) in oral lichen planus, epithelial dysplasias and squamous cell carcinomas. Br J Dermatol. 1997;136(3):331-6. 16. Kosmehl H, Berndt A, Strassburger S, Borsi L, Rousselle P, Mandel U, et al. Distribution of laminin and fibronectin isoforms in oral mucosa and oral squamous cell carcinoma. Br J Cancer. 1999;81(6):1071-9.

17. Lindberg P, Larsson A, Nielsen BS. Expression of plasminogen activator inhibitor-1, urokinase receptor and laminin gamma-2 chain is an early coordinated event in incipient oral squamous cell carcinoma. Int J Cancer. 2006;118:2948-56. 
18. Marangon Junior H, Rocha VN, Leite CF, de Aguiar MC, Souza PE, Horta MC. Laminin-5 gamma 2 chain expression is associated with intensity of tumor budding and density of stromal myofibroblasts in oral squamous cell carcinoma. J Oral Pathol Med. 2014;43(3):199-204.

19. Ono Y, Nakanishi Y, Ino Y, Niki T, Yamada T, Yoshimura K, et al. Clinocopathologic significance of laminin-5 gamma2 chain expression in squamous cell carcinoma of the tongue: immunohistochemical analysis of 67 lesions. Cancer. 1999;85:2315-21.

20. Peixoto da-Silva J, Lourenço S, Nico M, Silva FH, Martins MT, Costa-Neves A. Expression of laminin-5 and integrins in actinic cheilitis and superficially invasive squamous cell carcinomas of the lip. Pathol Res Pract. 2012;208(10):598-603.

21. Rani V, McCullough M, Chandu A. Assessment of laminin-5 in oral dysplasia and squamous cell carcinoma. J Oral Maxillofac Surg. 2013;71(11):1873-9.

22. Shruthy R, Sharada P, Swaminathan U, Nagamalini BR. Immunohistochemical expression of basement membrane laminin in histological grades of oral squamous cell carcinoma: A semiquantitative analysis. J Oral Maxillofac Pathol. 2013;17(2):185-9.

23. Thorup AK, Reibel J, Schiodt M, Stenersen TC, Therkildsen MH, Carter WG, et al. Can alterations in integrin and laminin- 5 expression be used as markers of malignancy? APMIS. 1998;106(102):1170-80.

24. Zargaran M, Eshqhyar N, Vaziri PB, Mortazavi H. Immunohistochemical evaluation of type IV collagen and laminin-332 $\gamma 2$ chain expression in well-differentiated oral squamous cell carcinoma and oral verrucous carcinoma: a new recommended cut-off. J Oral Pathol Med. 2011;40(2):167-73.
25. Tringler B, Grimm C, Dudek G, Horvat R, Zeilinger R, Hefler LA, et al. The lack of laminin-5 as a prognostic marker in low-grade cervical squamous intraepithelial lesions: correlation with clinical follow-up data. Int J Gynecol Pathol. 2007;26(1):89-94.

26. Imura J, Uchida Y, Nomoto K, Ichikawa K, Tomita S, Lijima T, et al. Laminin-5 is a biomarker of invasiveness in cervical adenocarcinoma. Diagn Pathol. 2012;17(7):105.

27. Ogawa T, Tsubota Y, Maeda M, Kariya Y, Miyazaki K. Regulation of biological activity of laminin- 5 by proteolytic processing of gamma2 chain. J Cell Biochem. 2004;92(4):701-14.

28. Patarroyo M, Tryggason K, Virtanen I. Laminin isoforms in tumor invasion, angiogenesis and metastasis. Semin Cancer Biol. 2002;12(3):197-207.

29. Goldfinger LE, Stack MS, Jones JCR. Processing of Laminin-5 and Its Functional Consequences: Role of Plasmin and Tissue-type Plasminogen Activator. J Cell Biol. 1998;14191):255-65.

30. Nguyen BP, Gil SG, Carter WG. Deposition of laminin 5 by keratinocytes regulates integrin adhesion and signaling. J Biol Chem. 2000;275(41):31896-907.

31. Pyke C, Salo S, Ralfkiaer E, Romer J, Dano K, Tryggvason K. Laminin-5 is a marker of invading cancer cells in some human carcinomas and is coexpressed with the receptor for urokinase plasminogen activator in budding cancer cells in colon adenocarcinomas. 1995; 55(18):4132-9.

32. Scanlon CS, Van Tubergen EA, Inglehart RC, D'Silva NJ. Biomarkers of Epithelial Mesenchymal Transition in Squamous Cell Carcinoma. J Dent Res. 2013; 92(2):114-21.

\section{Mini Currículo e Contribuição dos Autores}

1. Eline Manhães Reid Silva - cirurgiã-dentista e mestre. Contribuição: contribuição científica e intelectual efetiva para o estudo; concepção e delineamento; aquisição dos dados; interpretação dos dados; preparação e redação do manuscrito.

2. Letícia Côgo Marques - cirurgiã-dentista e especialista em Estomatologia. Contribuição: científica e intelectual efetiva para o estudo; concepção e delineamento; aquisição dos dados; interpretação dos dados; preparação e redação do manuscrito.

3. Kristian Cláudio Callegari - cirurgiã-dentista. Contribuição: científica e intelectual efetiva para o estudo; concepção e delineamento; aquisição dos dados; interpretação dos dados; preparação e redação do manuscrito.

4. Letícia Nogueira da Gama de Souza - cirurgiã-dentista e PhD. Contribuição: científica e intelectual efetiva para o estudo; concepção e delineamento; procedimentos técnicos e revisão crítica.

Recebido em: 05/01/2017 / Aprovado em: 09/03/2017

Autor Correspondente

Eline Manhães Reid Silva

E-mail: elinereid@gmail.com 